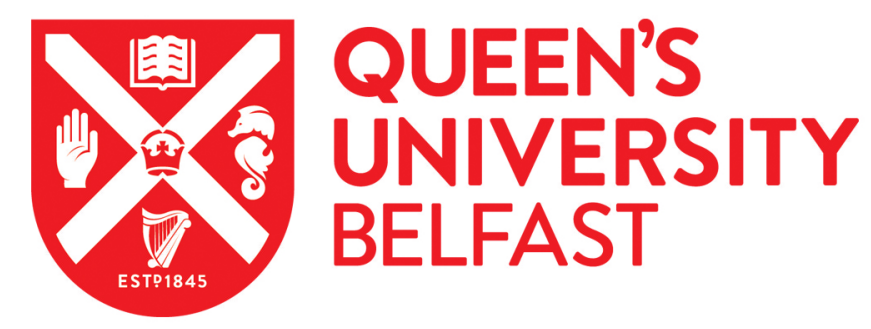

\title{
Integrated schools and intergroup relations in Northern Ireland: the importance of parents
}

Donnelly, C., Furey, A., \& Hughes, J. (2016). Integrated schools and intergroup relations in Northern Ireland: the importance of parents. Educational Research, 58(4), 442-456. https://doi.org/10.1080/00131881.2016.1232916

\author{
Published in: \\ Educational Research
}

\section{Document Version:}

Peer reviewed version

Queen's University Belfast - Research Portal:

Link to publication record in Queen's University Belfast Research Portal

\author{
Publisher rights \\ (c) 2016 NFER. \\ This is an Accepted Manuscript of an article published by Taylor \& Francis in Educational Research on 30th September 2016, available \\ online: http://www.tandfonline.com/10.1080/00131881.2016.1232916.
}

\section{General rights}

Copyright for the publications made accessible via the Queen's University Belfast Research Portal is retained by the author(s) and / or other copyright owners and it is a condition of accessing these publications that users recognise and abide by the legal requirements associated with these rights.

Take down policy

The Research Portal is Queen's institutional repository that provides access to Queen's research output. Every effort has been made to ensure that content in the Research Portal does not infringe any person's rights, or applicable UK laws. If you discover content in the Research Portal that you believe breaches copyright or violates any law, please contact openaccess@qub.ac.uk. 
Integrated Schools and Intergroup Relations in Northern Ireland: the importance of Parents

Corresponding author:

Caitlin Donnelly School of Education QUB, 20 College Green Belfast;

Caitlin.donnelly@qub.ac.uk 02890975943

Andrea Furey:

Room MC014

School of Psychology

University of Ulster

Magee campus

Londonderry

BT48 7JL

02871675468

a.furey@ulster.ac.uk

Joanne Hughes:

School of Education

QUB

69 University Street Belfast Joanne.hughes@qub.ac.uk 02890975934 


\title{
Integrated Schools and Intergroup Relations in Northern Ireland: the importance of Parents
}

Authors: Caitlin Donnelly; Andrea Furey; Joanne Hughes

\begin{abstract}
Background: Integrated schools were established in Northern Ireland in the early 1980s. With an explicit intention to build better relations between Catholics and Protestants, it has an intuitive appeal in a society which has long experienced sectarian division. Whilst the sector has attracted considerable research, less is understood about how parents' perceive the approach adopted by schools to build intergroup relations.
\end{abstract}

Purpose: The present article seeks to address the gap in the literature by exploring parents' views of integrated education. Drawing on theories of intergroup contact, the paper seeks specifically to explore how parents and Headteacherss perceive and negotiate the approach that the schools adopt to build intergroup relations.

Method: In an attempt to probe the deeper meanings that participants attach to integrated education, a qualitative research approach was adopted; semi structured interviews were carried out with 17 parents and 2 Head teachers in two integrated primary schools.

Findings: Through the data analyses, three main aspects were evident. Firstly, the study reveals something of the relational dynamic between Headteachers and parents and the significance of this relationship for determining how intergroup relations are pursued in integrated schools. Secondly, it highlights the nebulous nature of identity salience and the practical challenges of making identity salient within mixed identity contexts. Finally, the study suggests the value of qualitative approaches for exploring intergroup contact initiatives.

Conclusions:Overall, the paper demonstrates the inherent challenges of establishing an integrated school where good relations will be developed when multiple interpretations of what constitutes an appropriate response to difference and diversity prevails.

Keywords: Integrated Schools; Parents; Intergroup contact; Northern Ireland; identity salience

\section{Introduction}

\section{Background}


Since the inception of the Northern Ireland state in 1920, the two main communities in Northern Ireland have, in the main, educated their children in separate schools. Thus Catholics generally attend Catholic schools and Protestants attend state schools which are commonly perceived to be Protestant institutions. The schools are deeply intertwined with the communities that they serve and this point, well captured by Murray in his ethnographic study of Catholic and Protestant primary schools in the 1980s, still has resonance today:

There are two distinct communities in Northern Ireland, usually described in the religious terms of Roman Catholic and Protestant. Being a member of either community however entails much more than simply being of one or other religious persuasion. It involves the possession of values, traditions beliefs attitudes and aspirations all of which contribute to the culture of that community.... Any cultural analysis of Northern Ireland must take into account the peculiar position that schools occupy in that area. Religion, politics and culture are almost inextricably enmeshed. In general Protestants subscribe to a unionist political ideology and maintain their own cultural traditions ... which are largely a function of English or Scottish identity. Catholics and on the other hand aspire to varying degrees towards a nationalist ideal and possess a set of values and traditions emanating from and identifying with an Irish heritage....Schools exist as religiously polarised institutions serving each major cultural group (Murray 1985:7)

The almost total separation of the communities into different schools has long raised concerns about the implications of schooling for sustaining societal division, but efforts to change the system did not gain momentum until the 1970s when the outbreak of political violence focused attention on education as a contributory factor (Dunn 1990). Calls for the development of a mixed religious school system eventually culminated in the opening of the first integrated school, Lagan College, in 1981, and a further three schools followed in the 1980s. Established by parents, each school operated independently from government and was funded by parents and charitable organisations. However, by 1989 the government had accepted the viability of integrated schools. The 1989 Education Reform (Northern Ireland) Order granted public funding and accorded the schools statutory recognition. Moreover, a duty was placed on the Department of Education to 'encourage and facilitate integrated education'. As a result, the number of new schools grew throughout the 1990 s and some controlled or 'Protestant' schools changed their status to 'integrated'. These schools are designated 'Controlled Integrated' $(\mathrm{Cl})$ whilst the newly formed schools are known as 'Grant Maintained Integrated' (GMI); at the time of writing, 62 integrated schools educate 7 per cent of the population: this is comprised of 38 Grant Maintained Integrated schools and 24 Controlled Integrated schools; 20 post-primary and 42 primary schools (DE, 2016). Integrated education is promoted and supported by a charitable organisation - the Northern Ireland Council for Integrated Education [NICIE].

Given their unique position in Northern Ireland, it is perhaps unsurprising that integrated schools have attracted a substantial body of empirical research, although and significantly, evidence as to their capacity to effectively challenge group divisions remains notably inconclusive. So whilst research (see McGlynn et al, 2004; Hayes et al, 2007; Stringer et al 2009; Hansson et al 2013) has attested to the benefits of integrated education in terms of its capacity to allow young people to make cross-group friendships or break down negative attitudes, other research has been more cautious, suggesting that teachers can struggle to create a climate conducive to the pursuance of 'good intergroup relations' in schools (Donnelly, 2004a 2004b; Donnelly and Hughes 2006). Despite the extent of research however, less is understood about the perceptions of parents in these schools. So, whilst parents' reasons for choosing integrated schools have been explored (Dunn and Morgan 1999; Montgomery et al., 2003; Hansson, et al., 2013), how they perceive schools' attempts to build intergroup relations has attracted less attention. In some ways, this is not surprising: 
parents are not direct participants in the schools, and thus their views might be regarded as somewhat tangential to the experience that the schools seek to offer. However, the framing of parents as 'active citizens' and 'empowered actors' in educational policy frameworks since the 1980s (Munn, 1998), combined with the prominent role that parents have historically occupied in the establishment of integrated schools suggests that they are unlikely to be passive bystanders to the school; instead, it is likely that they will seek to shape and inform the way that the school engages with diversity (NICIE, 2012).

\section{Aim of the study}

The purpose of this paper is to explore how parents perceive schools' attempts to build an 'integrated ethos', by drawing on data from two integrated schools in Northern Ireland. It begins by briefly outlining the purpose of and theoretical concepts allied to integrated education, before presenting the research design and data.

\section{The integrated school ethos and theories of intergroup contact}

The stated purpose of integrated education in Northern Ireland is set out by NICIE:

Education together in a school of children and young people drawn mainly from the Protestant and Catholic traditions, with the aim of providing for them an excellent education that gives recognition to and promotes the expression of these two main traditions.... The core aim is to provide children and young people with a caring and enhanced educational experience thus empowering them as individuals to affect positive change in a shared society

(NICIE, 2012:2)

Whilst the aims of the integrated school have an inherent appeal in a society which has long been riven with sectarian tensions and political violence, theories of intergroup contact offer a theoretical lens through which to further understand their purpose and rationale. Proposed initially by Allport in 1954 and developed further since the 1980s (see for example: Stephan, 1987; Jackson, 1993; Brown et al, 1999; Dixon et al 2005 Pettigrew and Tropp 2006; Paolini et al, 2010; Pettigrew et al 2011; Dovidio et al 2011; Everett, 2013) the simple hypothesis states that where divided groups are brought together under certain conditions then prejudice may be reduced. It advises that the communities are represented equally within contact situations and that there are opportunities to allow participants to co-operate and sustain friendships (Allport, 1954; Pettigrew and Tropp, 2006). Significantly, a commitment to these ideals resonates through the policy documentation on integrated education. Thus the communities are to have equal status in so far as schools are to aim for a balanced pupil intake (schools should strive towards a ratio of at least 40:40 Catholic/Protestant and 20\% other) and Protestant and Catholic children should have prolonged and co-operative intergroup contact by virtue of their enrolment in the school (NICIE, 2012). Yet, and significantly, the emphasis on building relations in integrated schools extends well beyond the preservation of a balanced enrolment or simply making friends. Rather, there is an acknowledgement of the broader societal divisions and the extent to which these inherently shape and determine how young people understand themselves and others. Efforts are made to engage therefore with the differences between groups and to explore the particular identity needs of the diverse range of pupils represented in the schools. Hence, it is stated that the schools should support 'young people from Catholic and Protestant backgrounds, as well as those of other faiths and none, (to learn) with, from and about each other' (NICIE, 2012: 2). 
That emphasis is placed on identity exploration and difference is perhaps not surprising for those seeking to build intergroup relationships in a divided society. Indeed, the literature seems replete with references to its importance. So whilst Gaertner and Dovidio (2012) and Pettigrew and Tropp (2006) have reflected on the anxieties provoked by exploring identity in mixed group contexts there is, nonetheless, an acceptance that contact is more likely to generalise and have a more enduring effect on relations when participants are made aware of each other's group identities:

We conclude that the positive effects of contact can be heightened by maintaining the salience of categories rather than by de-emphasizing them as some have suggested. .... the achievement of true and lasting change in intergroup attitudes may not always be best achieved by ignoring or overlooking existing category divisions (Brown et al, 1999:761)

However, the capacity of integrated schools to realize their ambitions around contact generally, and identity salience in particular, is not guaranteed. For Allport (1954) and, more recently Pettigrew and Tropp, a sympathetic 'local atmosphere' is deemed pivotal to the efficacy of the contact process (Pettigrew and Tropp, 2006:766). Significantly, the notion of the 'local atmosphere' or the associated concept of 'institutional support' is not imbued with a precise definition. However, it remains an important idea in contact theory because it necessarily lends emphasis to the views of those who are invested in, but perhaps external to the immediate contact environment when exploring contact processes (Koschate and Vandick,2011). This is a particularly significant issue for schools where adults, including parents, are positioned to play a vital role in facilitating the normative and structural context within which contact takes place (Walker and Crogan, 1998). Indeed, there has been a focus on the marketization of schooling since the 1980s, which has sought to recast the 'passive parent' as an 'empowered actor' within the educational arena. This, combined with the integrated school's emphasis on fostering strong relationships with parents, means that the views of parents in respect of the development of the contact experience is something that merits deeper exploration (Munn, 1998; Gilbert, 2012).

The research approach

Quantitative research, emanating largely from the discipline of social psychology, has offered conclusive and compelling evidence that contact reduces prejudice (Pettigrew and Tropp 2000; 2003). The large-scale surveys, which measure attitudes towards the 'other' group, and the experimental data, which explore how participants respond to the 'other' have been instrumental in raising our awareness of the importance of Allport's conditions for enabling positive contact (Pettigrew and Tropp, 2006). However, and notwithstanding the obvious contribution of extant quantitative research, there remains a notable absence of qualitative data in the field. Consequently, there is less understanding of how participants interpret the contact experience and in particular, what they see as normal and acceptable behaviour within everyday contact situations. Exploring contact in real life situations therefore helps us better appreciate the feelings and emotions that are provoked when historically divided groups interact (see Connolly, 2000; Dixon et al 2005). Additionally, and as Zembylas and Bekerman (2016: 216) suggest, because research on intergroup relations is dominated by 'psychologised research which refuses to confront noise, that is to say complexity' it is necessarily limited in its attempts to reflect the complex and 'fuzzy' elements of relationship building'. Our focus in this paper and our intention is, therefore, to draw on qualitative data to explore the complex reality of the integrated school, as it is perceived by parents and head teachers. Reflecting the qualitative research design, the research was guided by two central questions:

- How do parents and Headteachers lend meaning to the ethos of the integrated school? 
- How do parents and Headteachers interpret the concept of identity salience?

\section{Ethical approval and access}

Primary schools were selected as the site of data collection because parents are recognized as being more closely connected to primary schools and thus are potentially more aware of how the school was engaging with the processes of inter-group relationship building (Goodall and Vorhaus, 2011). Gaining access was more difficult than first anticipated. The majority declined to take part on the basis that they were too busy to accommodate researchers. The two schools which agreed to take part were of a similar size and were located in different towns. In line with NICIE guidelines each school enrolled at least a 60:40 balance of pupils, staff and governors from the two main communities as well as a minority of children from ethnic minority backgrounds (school websites). ${ }^{1}$. Birch et al (2012) argue that researchers should think ethically in order to protect themselves and their participants in research projects. Given the potentially sensitive issues that we were intending to explore, the need to 'think ethically' took on even greater significance within this project. Particular attention was paid to the University and BERA guidelines on research ethics prior to and during the process of data collection and writing up. The Ethics Committee in the School of Education where two of the team was employed granted approval for the research to proceed on the basis that we observed ethical guidelines: To ensure informed consent, an information letter was initially sent to principals to explain the overall goals of the research and to invite their participation. Assurances were given in this letter with regard to voluntary participation, confidentiality and anonymity. Contact information was provided so that the principals could discuss the research before granting approval. The principals of both schools orally discussed the research before offering their consent. After institutional consent was granted, an information letter and consent form was forwarded to all parents via the principal and those parents who wished to take part were offered the contact details of the researchers to discuss the research. Parents were also assured that although the principal had permitted the research to proceed they should not feel under any obligation to take part. A small number of parents in each school returned signed forms consenting to interviews. Consent was offered on the basis that neither they nor their school would be identified in any report or paper arising from the research. All participants agreed that the interviews could be audio-recorded and transcribed. They also agreed that anonymized quotations could be used in reports and journal articles. All participants were offered an opportunity to retrospectively withdraw from the research until the date of data anonymization [two months after data collection] but no participant chose to do so.

Whilst observing ethical protocol is important in any research, ethical issues are compounded when undertaking qualitative research on sensitive topics (Taylor, Bogdan and DeVault, 2016). As qualitative researchers, we needed to be able to build a rapport with our participants in order to facilitate the disclosure of information, (see Kvale, 1996). Yet in two of the early interviews we struggled to foster such a rapport largely [we believed] because of the general tendency in Northern Ireland to avoid the discussion of issues related to the conflict (see McGrellis, 2004; Niens et al 2013). As prior research advises that researcher disclosure can assist in building relations between interviewer and interviewee when discussing sensitive issues the team sought, [in subsequent interviews], to create what Dickson- Swift et al (2007) refer to as a 'level playing field' by freely offering information about our own identity and our experiences of growing up in Northern Ireland. This, combined with a decision to reassure participants about confidentiality and anonymity at the beginning of all interviews, seemed to create a more conducive and safe atmosphere for the sharing of information.

\section{Data collection}

${ }^{1}$ The authors are deliberately vague to protect the identity of schools and participants. 
The first task was to review the official school documentation. The school prospectus and the school websites, in particular, allowed the researchers to become acquainted with the schools and the official statements on ethos. They also offered an insight into the role that parents assumed in the school as well as the general policies pursued therein. In both schools, the Parents' Council had regular meetings and this seemed to serve as a social outlet for parents as well as a place where they could organize fundraising activities and articulate views on the school to staff. Single interviews were undertaken with 17 parents, almost equally divided across both schools, and with both headteachers. Whilst parents were the focus of the research, interviews with the Headteachers were also a key part of the research design because it was believed that their views would help us better appreciate the ways in which the institutional structures supported the contact endeavour. Both Headteacher interviews lasted around 1-2 hours. As the data below illustrate, the Headteachers were open and forthcoming during interview. In School A, informal conversations with the Head also occurred throughout the research period. This was because the researchers were visiting the school frequently over the 4 week period to interview parents. In School B it was agreed with the Headteacher that the parents would be interviewed in their own homes.

\section{Participants}

As we were keen to explore how parents perceived the process of building intergroup relations, it was important to involve parents that were familiar and engaged with the school. Thus, all parents were involved in the schools either as school volunteers, as current or past members of the governing body or as members of the Parents' Council. No fathers responded to the invitation to participate: hence, the data was collected only from mothers.

\section{Data collection and analysis: issues of reflexivity}

Finlay (2001) has lamented the predilection of academic researchers to maintain a personal distance from the conflict and to present non-reflexive accounts of the dynamics of intergroup relations in Northern Ireland. In an attempt to mitigate these concerns, we were anxious not to frame ourselves as neutral but instead we paid careful attention to our own perspectives prior to and during data collection, analysis and writing up. The researchers are all from Northern Ireland: one is from a Catholic background, one from a Protestant background and one was brought up in a mixed religious background. All three attended the interviews with the Head-teachers and the majority of parent interviews. The remaining interviews were conducted by either the researcher from the mixed background or by the Catholic and Protestant researchers.

After the interview data was fully transcribed, our concern was to lend meaning to the emergent findings. In analysing the data we were influenced by the work of Boyatzis (1998:- vii) who argues for a thematic analysis of qualitative data whereby the researcher develops "codes," words or phrases that serve as labels for sections of data. Flick (1998:188) explains that 'thematic coding is applied as a multi-step procedure' and we similarly adopted a phased approach to the data analysis. At first, we independently identified broad emergent categories within the data. We then discussed our individual categories seeking to find consensus amongst the research team. As we sought to identify and agree on broad, patterns and themes relevant to the research questions, however, we began to recognise how our own inherent subjectivities as Catholics and Protestants had influenced the ways in which we made sense of the data (Bott 2010). Yet, as qualitative researchers, we do not see this subjectivity as a weakness but rather in the discussions that followed between us, particularly those around issues of identity expression within educational contexts, we felt that we began to better empathise with the worlds that the participants inhabited and the tensions that they sought to balance within the integrated school environment (Russell and Kelly, 2002). In the third 
reading of the data, we unanimously agreed on the key themes that were prevalent across all interviews. These themes structure the presentation of data below.

\section{Perceptions of the integrated ethos}

Initial questions sought to explore parents' reasons for choosing an integrated school for their child. All of the parents expressed an ideological commitment to integrated education and the belief that integrated schools would challenge social division was prevalent across all interviews. Most were adamant that their children would not be exposed to the sectarianism that they had experienced in their own lives and in this sense the integrated school represented a space where hopes for a new Northern Ireland could be realised:

This is a great school; there is a real commitment to the principles of integrated education, you know ....to really build on bringing children together and to learn about each other (parent, School B)

The draw for me was to really get them together so they didn't grow up in the way that I did with segregation. I didn't want that - we had our lives ruined; I wanted a change for my kids; I think these schools are the future (parent, School A)

When asked to describe how the integrated ethos worked in practice, participants readily supplied examples of the different ways in which the school engaged with the identities represented. All participants agreed that efforts were made to ensure that children understood the different religious practices that were associated with each community. Catholic and Protestant parents across both schools mentioned the Catholic religious sacrament of First Communion as a key mechanism through which children could learn about religious identity. In School A, a tradition had evolved whereby the Catholic children made their First Communion in Church and were joined afterwards by their Protestant classmates. A number of parents referred to this as an exemplar of the ethos in practice, for example:

I can say we definitely don't leave our identity at the door we celebrate that; thinking about First Communion it was wonderful that the children... the Protestant children helped organise the after party in the school that was a real testament to the strength of relations. The thing here is..... Here your religion is emphasised, it is catered for and you can prepare for the sacraments........it's the fact that religion is highlighted....and children are taught about all sorts of religions ...

Parents in School B similarly lent emphasis to the ways in which religious differences were explored and many suggested that celebrating faith differences had been 'hugely successful' in lessening their children's fear of the 'other':

We do all the main celebrations of different faiths and we have different speakers in from [mentions a particular faith group] and all the different faiths. I like it that integration is open to that.

The data initially suggested then that there were strong synergies between parents and the Headteachers in each school with regard to the meaning of the school ethos. Efforts to explore religious identity and attempts to foster familiarity with the range of church buildings and religious traditions of the groups seemed to find favour with parents who believed that the schools should actively challenge fears around religious difference by developing children's knowledge and understanding. Yet, and as noted by Murray (1985), to define the conflict in wholly religious terms is 
to overlook the intertwining of its political and historical facets. It is these that arguably require much closer analysis in any mixed group situation in Northern Ireland (Ganiel and Dixon, 2008). Hence, it was important to capture parents' perspectives in relation to how the school facilitated the expression of political and historical aspects of identity. It was at this point that some distinctions began to emerge between the schools, as is explained further below:

\section{Dealing with conflict-related issues: Masking identity difference in School A}

For the majority of parents in School A, exploring national identity, or the ways in which group difference manifested in the local political-social context, was considered to be largely peripheral to the ethos of the school. Parents generally did not believe that these aspects of identity merited discussion within the school, as is evident below:

You have explained that the schools deal well with religious difference. What about other aspects of identity, such as those related to being British or Irish?

Yes our school would engage with differences of course as I said earlier... but, look, we have to remember too that the children need to know it is just stupid to fight with people that you don't even know or haven't even talked to and so I know the [class] did about being kind to others. To me that is the job done and that is the ethos in this school we get along great as it is so don't knock it ...

\section{Do you think that the school should explore such issues?}

I don't think really that anybody really cares (about difference). ..... It is never brought into this school and I think that is just fantastic; the school has got it absolutely right;

The Headteacher rehearsed a similar view. Similiar to the parents, the headteacher spent much time during her interview explaining how the school explored difference. The headteacher referred to the examples supplied by the parents above but also provided others although these were notably unrelated to the Northern Ireland context:

It's funny last month ...there was a nice event for the [class] with looking at the African culture as we have a pupil from [country] in that class. That was really fascinating to see children understand the lovely richness that comes from interacting with different children ...really beautiful event.

What about other aspects of difference related to the Northern Ireland conflict-are they discussed, given that most parents here are local?

We wouldn't overly focus on Northern Ireland history or politics ... we do as I say the church differences ... but the conflict ...there wouldn't be any appetite amongst the parents for that. I wouldn't know of any parent who would be pushing for that kind of stuff it would be the opposite they wouldn't want it and we would be very neutral... and not trying to sectarianise things... ....the differences that you refer to funny enough wouldn't come up here in this school; ...people are not concerned with that kind of stuff ... we don't want to jeopardise the relations we have too. We know it's there, but it is important not to get overly caught up in that as a school. ....

Despite the importance of identity salience for facilitating the generalisation of contact effects (Brown et al, 1999), the data above echo concerns raised by Gaertner and Dovidio (2012), which suggest that open discussion of identity can provoke apprehension in mixed groups. The data also, however, cast light on the meaning attributed to identity salience in contested contexts. 
Specifically, it reveals 'identity salience' to be a multi-faceted concept and suggests that some facets of identity will be more difficult to make salient than others. Thus, whilst the expression of religious identity was deemed innocuous and suitable for exploration within the school, any engagement with political or national identity was regarded by most participants as socially perilous and deeply antithetical to the reconciliatory aims of the school. Consequently, strict cultural parameters existed to limit rather than facilitate their expression. Yet, and interestingly, where the data suggested that the social strictures pertaining to national identity expression were generally accepted as 'normal' by participants, one parent defined such practices as 'frustrating' for those who sought a different approach. Whilst her comments were not rehearsed by others, they are worth mentioning not least because she highlighted the intricacies of relationship-building in conflicted societies and the difficulties that arise when there are restrictions placed on the full expression of identity within schools. She specifically argued that striving for neutrality was an inherently futile endeavour, not least because it failed to acknowledge the multiplicity of perspective that inevitably exists within schools and lessens the need to incorporate diverse voices into the decision-making process.

This suggests that although previous research has also attested to the existence of social norms in Northern Ireland which dictate that issues related to the conflict ought not to be discussed in mixed group company (Liechty and Clegg, 2001), the prevalence of such norms within integrated schools may have negative implications for the evolution of intergroup relations. Specifically, where norms suggest that participants cannot express identity and where there is a cultural pressure not to disrupt a dominant discourse of 'neutrality', then decisions are likely to be made and policies pursued in the absence of reflexive discussion about the differential implications which they may have for particular groups. Indeed the harmonious relations that were frequently referred to by participants may belie and indeed distract from social processes which serve to institutionalise rather than challenge the discriminatory practices that are inextricably linked to and fuelled by sectarianism (Crozier and Davies, 2007; Dixon et al, 2005).

\section{Dealing with difference: Making Identity Salient: Evidence from School B}

In School B, a very different approach to identity salience was adopted compared with that in School A. Specifically, rather than striving to impose a culture of commonality, the Head was explicitly concerned to engage in open explorations of religious, political and national identity. The school had hosted visits from the range of political parties, displayed British and Irish flags and discussed the importance of other symbols resonant of the respective identity groups. The headteacher argued that the exploration of all aspects of identity and difference was essential in an integrated school as this would facilitate discussion amongst pupils and teachers and create a space where individuals were not only less anxious when encountering the culture of the 'other' but had a more fundamental appreciation of the 'roots of the conflict':

Some things that happen as you go along such as 'somebody called me a whatever, a Protestant etc'. It's about not saying 'you'll be grand'. It's about saying 'let's talk about it'. 'So what is that? What's that about?' So it's really about looking at it and addressing issues as well as sometimes having that as part of the program where you are looking at where you are from. From primary one, they know who they are...You know that research? ..... So it's about unpicking some of that baggage in a safe environment where there is some kind of trust built up. So part of it is kind of hidden in a way but some of it has got to be kind of overt as well. 
Although she readily accepted that some parents were dissatisfied with the expression of national identity, the Headteacher was confident that this was the 'best' way to lend practical effect to the ethos and her views prevailed. Thus she explained:

We are not going to be polite or anything like that about it. We are going to kind of address whatever issues come up so that is part of what you are buying into to....

The headteacher's comments seemed to capture the essence of an ethos that aspires to 'celebrate difference' and appear to neatly reflect notions of effective intergroup contact outlined earlier: The Head was keen that national and political identity was made salient and that children through their exposure to the historical, religious and political manifestations of group identity will foster relations not only at the inter-personal level but also as members of groups that are divided within the context of Northern Ireland (Brown et al 1999; Ganiel and Dixon 2008). Unlike the Head teacher in School A, the Head in School B sought to explore the affiliations of the different groups and their politico-cultural proclivities on the basis that exposure to such knowledge would inevitably challenge negative stereotypes. As noted, the head based the approach on a reading of the academic literature in the field and in this regard was confident of its appropriacy within the school. Some parents concurred with the headteacher's assessment and the following typified their response:

It is good in a way to be aware of the issues, aware of the history and aware of that is where we are and that is why it is so important that we are in an integrated school. I don't like hiding it away and not knowing anything..

Yet, and as the Headteacher acknowledged, other parents did not believe that such 'honesty' was consistent with the development of more positive inter-group relations. Rather, they were concerned that the frequent reference to the Northern Ireland conflict was stifling the academic progress of pupils and prompting unnecessary friction between parents and teachers. Some parents were dissatisfied that the Head had not acted on their fears and so felt compelled to remove their children from events and classes that, they argued, were deeply unsuitable for discussion in an integrated school. As one parent reflected,

With any school, you are not necessarily going to think that everything is fantastic but there is an over-drive to be seen as integrated. .... I'm only happy with that if they are teaching the full curriculum.

Gaertner et al (2012) have argued that salient intergroup boundaries are often associated with mutual distrust and anxiety. Whilst the data above lend emphasis to their argument it specifically exemplifies the struggles that can occur when schools encourage the expression of political and historical aspects of identity without full recourse to the parental view. That some parents sought to remove their children from events deemed 'too controversial' suggests a depth of emotional and social discomfort around the expression of national identity that was not fully appreciated by the Head teacher and which had the potential to undermine the process of intergroup relationship building. Hence, any decision to relegate the dissenting parental voice in this context potentially compromises the extent and depth of 'institutional support' offered to the contact situation. However, it is this very support, as argued earlier, that is likely to be critical if the contact process is to challenge negative intergroup relations (Allport, 1954; Pettigrew and Tropp, 2006).

Building intergroup relations in schools: the importance of fostering informed dialogue with parents 
Reconciling the tensions outlined above is difficult. However, two parents (one from each school) suggested that accepting the inherent heterogeneity of the views of the parent community and acknowledging that their perspectives will not always coalesce with the headteacher in terms of the construction of intergroup relations was critical if relations were to be fostered between the groups. They argued that as some parents and teachers simply did not believe that integrated schools should engage with 'contentious' identity-related issues, efforts needed to be invested by schools to raise parent and professional consciousness of the value of such engagement:

I have sent all of my children to this school ... and we don't think enough about how to incorporate the parent view. I haven't said anything .... But I think there needs to be a sort of programme for parents and teachers so that we sort of come to an agreement that people are not on the same page in terms of talking about our differences. Everyone talks about discussing difference as though they know what that means but everyone means different things. Some ...Most people think that means talking about like different churches but not the flags or say the politics or something that causes tension whereas others like me think that it all has to be discussed with kids. I think we need to start a conversation; maybe engage with what goes on in the research ... at least talk with other parents and teachers about the ethos ... or it could start to undermine the school ...(parent School A)

Parental support of various kinds is obviously not a new idea and has been presented as 'good practice' in other studies of parental involvement (Goodall and Varhaus, 2011). However the role that parental learning might play in regard to assisting parents to support schools to build intergroup relations has perhaps not been as widely acknowledged. Creating spaces for parents drawn from different identity groups, particularly those in decision making roles, to reflect on the purpose of the integrated school has a potential to address some of the disparities in perspective that were highlighted throughout the data. For example, inviting parents to discuss the meaning of integrated education may lay bare their embedded assumptions and multiple perspectives around intergroup contact. Additionally, and with particular reference to identity salience, such discussion can also offer parents (and teachers) an opportunity to acknowledge, negotiate and make sense of the obvious emotions that identity salience might elicit for them and others. Thus, and as Tatum (1992) has shown, when US college students engaged with theories of identity development they began to better understand, legitimise and articulate their emotions around racial identity, difference and conflict. Crucially, they also became more receptive to exploring divisive issues and more empathetic to the reasons why others might refrain from such discussions. Presenting parents and teachers with similar opportunities may dispel the tensions and fears around making identity salient that were constantly apparent in the data presented above. Indeed, in the absence of informed dialogue between professionals and parents, it is possible that integrated schools may inadvertently reinforce the boundaries that they set out to challenge (Liechty and Clegg, 2001).

\section{Conclusion}

The purpose of this paper was to explore how parents and principals lend meaning to the ethos of the integrated school and to examine how participants interpret the concept of identity salience. Drawing on qualitative data from two primary schools in Northern Ireland, the paper has shown that, whilst parents and Headteachers agreed that building relations schools necessarily demanded an exploration of religious differences, there were divergent perspectives on how schools should deal with issues relating to political or national identity in Northern Ireland. Despite an official emphasis on parental involvement within integrated schools, there was little evidence that the multiplicity of parental voices was reflected in the approach taken by Headteachers with respect to developing the integrated ethos of the school. Rather, it seemed that the Head-teachers defined the school ethos in their own terms and determined what was right wrong and possible in regard to it. 
Whilst the qualitative nature of the research means that it is not possible to generalise from the data and we are acutely aware that the data represents only a 'moment in time', the paper does nonetheless, raise issues that are worth highlighting:

Firstly, it sheds light on the relational dynamic between Headteachers and parents and the significance of this relationship for determining how intergroup relations are pursued in integrated schools. It was argued earlier that parents, recast as empowered actors and active citizens, are now in a position to negotiate the school's approach to building relations with Headteachers. Yet, from the data we collected in both schools, there appeared to be little evidence of such negotiation. Rather, the data suggested that there was a tendency for Headteachers to homogenise the parental perspective and that the voices of those who expressed views about contact that ran counter to their own became relegated. . It is argued, however, that where parental voice is limited, this can compromise the capacity of schools to build intergroup relations. This is either because the Headteacher can potentially absolve the school of any need to explicitly examine divisive issues (as in School A), or the local support for the contact endeavour which Allport (1954) and Pettigrew and Tropp (2006) regard as pivotal for the realisation of better inter-group relations is not guaranteed (as in School B).

Secondly, the paper has lent clarity to the notion of identity salience and the practical challenges of making identity salient within integrated school contexts. It has been argued that where mixed groups are brought together in educational spaces identity salience enhances prospects of creating better intergroup relations (Brown et al, 1999; Everett, 2013). However, the paper has shown that identity salience is both complex and multi-faceted and in mixed group contexts not all aspects of identity are understood as equivalent. For example, the discussion of some differences such as those related to politics or the conflict generate more disputation and discomfort than others (perhaps religious differences). Whilst Tatum (1992) argues that engagement with more divisive issues holds the key to building positive inter -group relations in educational contexts, the data resonate with her assessment that greater sensitivity to participant readiness to engage with divisive issues is also a critical component of the intergroup relationship building process. It was clear from the data that not everyone was at a similar stage of readiness to engage with more politically charged issues and that parents who were not ready to discuss identity related issues could become disengaged from the school when the Headteacher promoted such discussion without taking cognisance of their concerns (Emerson et al, 2014). Thus recognising the delicate complexities embedded in the concept of 'identity salience' and judging readiness to engage with the more contentious facets of identity seems, therefore, to be a critical factor in any discussion around the construction of a school ethos that aims to celebrate diversity.

Finally, the paper highlights the value of qualitative research approaches for exploring intergroup contact initiatives. As noted earlier, the predominance of quantitative methodologies in the field of contact research have left gaps in the literature in relation to how contact is understood and lived out in 'real life situations' (Dixon \& Reicher,1997; Dixon et al, 2005; Bekerman and Zembylas, 2012; Bekerman and Zembylas, 2016). In paying attention to the way that participants interpret and make sense of contact, identity and difference, the paper has suggested some of the different ways in which inter-group relationship building is constructed by key players in the contact situation. It has also demonstrated the inherent challenges of establishing an integrated school, where good relations will be developed when multiple interpretations of what constitute an appropriate or 'normal' response to contact, difference and diversity prevails.

\section{References}

Allport, G. W. 1954. The Nature of Prejudice. Cambridge, MA: Perseus Books. 
Bekerman, Z., and M. Zembylas. 2012. Teaching Contested Narratives: Identity Memory and Reconciliation in Peace Education and Beyond. Cambridge: Cambridge University Press.

Bekerman, Z., and M. Zembylas. 2016. "Identity Negotiations in Conflict-Ridden Societies: Historical and Anthropological Perspectives." Paedagogica Historica. 52 (1-2): 201-218.[Taylor \& Francis Online], [Web of Science ${ }^{\circledR}$ ]

Birch, M., T. Miller, M. Mauthner, and J. Jessop. 2012. "Introduction." In Ethics in Qualitative Research, edited by M. Mauthner, M. Birch, J. Jessop, T. Miller, 1-13. London: Sage.[CrossRef]

Bott, E. 2010. "Favourites and Others: Reflexivity and the Shaping of Subjectivities and Data in Qualitative Research." Qualitative Research 10 (2): 159-173.10.1177/1468794109356736[CrossRef], [Web of Science ${ }^{\circledR}$ ]

Boyatzis, R. E. 1998. Transforming Qualitative Information. Cleveland, OH: Sage.

Brown, R., J. Vivian, and M. Hewstone. 1999. "Changing Attitudes through Intergroup Contact: The Effects of Group Membership Salience European." Journal of Social Psychology. 29: 741-764.[Web of Science $\left.{ }^{\circledR}\right]$

Connolly, P. 2000. "What Now for the Contact Hypothesis? Towards a New Research Agenda." Race, Ethnicity and Education 3 (2): 169-193.[Taylor \& Francis Online], [CSA]

Crozier, G., and Jane Davies. 2007. "Hard to Reach Parents or Hard to Reach Schools? A Discussion of Home-School Relations, with Particular Reference to Bangladeshi and Pakistani Parents." British Educational Research Journal 33: 295-313.10.1080/01411920701243578[Taylor \& Francis Online], [Web of Science ${ }^{\circledR}$ ]

Department of Education. 2016. Integrated Schools. Accessed September 2016. https://www.education-ni.gov.uk/articles/integrated-schools

Dickson-Swift, V., E. James, S. Kippen, and P. Liamputtong. 2007. "Doing Sensitive Research: What Challenges Do Qualitative Researchers Face?" Qualitative Research 7 (3): 327353.10.1177/1468794107078515[CrossRef]

Dixon, J., and S. Reicher. 1997. "Intergroup Contact and Desegregation in the New South Africa." British Journal of Social Psychology 36: 361-381.10.1111/bjso.1997.36.issue-3[CrossRef], [Web of Science ${ }^{\circledR}$ ], [CSA]

Dixon, J., K. Durrheim, and C. Tredoux. 2005. "Beyond the Optimal Contact Strategy a Reality Check for the Contact Hypothesis." American Psychologist 60: 697-711.10.1037/0003066X.60.7.697[CrossRef], [PubMed], [Web of Science ${ }^{\circledR}$ ]

Donnelly, C. 2004a. "What Price Harmony?" Teachers' Methods of Delivering an Ethos of Tolerance and Respect for Diversity in an Integrated School in Northern Ireland, Educational Research 46: 3-16.

Donnelly, C. 2004b. "Constructing the Ethos of Tolerance and Respect in an Integrated School: The Role of Teachers." British Educational Research Journal 30: 263278.10.1080/0141192042000195254[Taylor \& Francis Online], [Web of Science ${ }^{\circledR}$ ] 
Donnelly, C., and J. Hughes. 2006. "Contact, Culture and Context: Evidence from Mixed Faith Schools in Northern Ireland and Israel." Comparative Education 42: 493516.10.1080/03050060600988395[Taylor \& Francis Online], [Web of Science ${ }^{\circledR}$ ]

Dovidio, J. F., A. Eller, and M. Hewstone. 2011. "Improving Intergroup Relations through Direct, Extended, and Other Forms of Indirect Contact." Group Processes \& Intergroup Relations 14: 147160.10.1177/1368430210390555[CrossRef], [Web of Science ${ }^{\circledR}$ ]

Dunn, S. 1990. A Short History of Education in Northern Ireland 1920-1990. A Paper Prepared for the Standing Advisory Commission on Human Rights. Centre for Study of Conflict, University of Ulster, Belfast.

Dunn, S., and V. Morgan. 1999. "A Fraught Path: Education as a Basis for Developing Improved Community Relations in Northern Ireland." Oxford Review of Education 25: 141-153.[Taylor \& Francis Online], [Web of Science ${ }^{\circledR}$ ], [CSA]

Emerson, L., K. Orr, and P. Connolly. 2014. Evaluation of the Effectiveness of the Prison to Peace: Learning from the Experience of Political Ex-Prisoners' Educational Programme. Belfast: Centre for Effective Education, Queen's University Belfast.

Everett, J. A. C. 2013. “Intergroup Contact Theory: Past, Present, and Future.” In-Mind, 17.

Finlay, A. 2001. "Reflexivity and Identification in Northern Ireland." In Researching Violently Divided Societies, edited by M. Smyth and G. Robinson, 55-76. London: Pluto Press.

Flick, U. 1998. An Introduction to Qualitative Research. London: Sage.

Gaertner, S. L., and J. F. Dovidio. 2011. "Reducing Intergroup Bias: The Common Ingroup Identity Model." In Handbook of Theories of Social Psychology, edited by P. Van Lange, A. Kruglanski and E. T. Higgins, 439-457. London: Sage.

Gaertner, S., and J. Dovidio. 2012. Reducing Intergroup Bias: The Common In-group Identity Model. New York: Routledge.

Ganiel, G., and P. Dixon. 2008. "Religion, Pragmatic Fundamentalism and the Transformation of the Northern Ireland Conflict." Journal of Peace Research 45 (3): 419436.10.1177/0022343308088819[CrossRef], [Web of Science ${ }^{\circledR}$ ]

Gilbert, C. 2012. Towards a Self-Improving System: The Role of School Accountability. Nottingham: National College for School Leadership.

Goodall, J., and J. Vorhaus. 2011. Review of Best Practice in Parental Engagement. London: Institute of Education.

Hansson, U., U. O'Connor Bones, and J. McCord. 2013. Integrated Education: A Review of Policy and Research Evidence 1999-2012. Belfast: The Integrated Education Fund.

Hayes, B., McAllister, and L. Dowds. 2007. "Integrated Education, Intergroup Relations, and Political Identities in Northern Ireland." Social Problems 54: 454-482.10.1525/sp.2007.54.4.454[CrossRef], [Web of Science ${ }^{\circledR}$ ] 
Jackson, J. W. 1993. "Contact Theory of Intergroup Hostility: A Review and Evaluation of the Theoretical and Empirical Literature." International Journal of Group Tensions 23: 43-65.[CSA] Koschate, M., and R. van Dick. 2011. "A Multilevel Test of Allport's Contact Conditions." Group Processes \& Intergroup Relations 14: 769-787.10.1177/1368430211399602[CrossRef], [Web of Science $\left.{ }^{\circledR}\right]$

Kvale, S. 1996. InterViews: An Introduction to Qualitative Research Interviewing. London: Sage.

Liechty, J., and C. Clegg. 2001. Moving beyond Sectarianism. Dublin: Columba Press.

McGlynn, C., U. Niens, E. Cairns, and M. Hewstone. 2004. "Moving out of Conflict: The Contribution of Integrated Schools in Northern Ireland to Identity, Attitudes, Forgiveness and Reconciliation." Journal of Peace Education 1: 147-163.10.1080/1740020042000253712[Taylor \& Francis Online]

McGrellis, S. 2004. Pushing the Boundaries in Northern Ireland: Young People, Violence and Sectarianism. London: Families and Social Capital ESRC Research Group, London South Bank University.

Montgomery, A., G. Fraser, C. McGlynn, A. Smith, and T. Gallagher. 2003. Integrated Education in Northern Ireland. Integration in Practice Report 2. Coleraine: UNESCO centre, UU.

Munn, P. 1998. "Parental Influence on School Policy: Some Evidence from Research." Journal of Education Policy 13: 379-394.10.1080/0268093980130306[Taylor \& Francis Online]

Murray, D. 1985. Worlds Apart: The Character and Culture of Catholic and Protestant Schools in Northern Ireland. Belfast: Appletree Press.

NICIE. 2012. "Statement of Principles for Integrated Schools." Accessed June 2016. http://www.nicie.org/wp-content/uploads/2012/08/Statement-of-Principles.pdf

Niens, U., U. O'Connor, and A. Smith. 2013. “Citizenship Education in Divided Societies: Teachers' Perspectives in Northern Ireland." Citizenship Studies 17 (1): 128141.10.1080/13621025.2012.716214[Taylor \& Francis Online], [Web of Science ${ }^{\circledR}$ ]

Paolini, S., J. Harwood, and M. Rubin. 2010. "Negative Intergroup Contact Makes Group Memberships Salient: Explaining Why Intergroup Conflict Endures." Personality and Social Psychology Bulletin 36: 1723-1738.10.1177/0146167210388667[CrossRef], [PubMed], [Web of Science $\left.{ }^{\circledR}\right]$

Pettigrew, T., and L. Tropp. 2006. "Interpersonal Relations and Group Processes." Journal of Personality and Social Psychology 90 (5): 751-783.[CrossRef], [PubMed], [Web of Science ${ }^{\circledR}$ ]

Pettigrew, T., L. Tropp, U. Wagner, and Oliver Christ. 2011. "Recent Advances in Intergroup Contact Theory." International Journal of Intercultural Relations 35 (3): 271280.10.1016/j.ijintrel.2011.03.001[CrossRef], [Web of Science ${ }^{\circledR}$ ]

Russell, Glenda M., and Nancy H. Kelly. 2002. "Research as Interacting Dialogic Processes: Implications for Reflexivity [47 Paragraphs]." Forum Qualitative Sozialforschung/Forum: Qualitative Social Research 3 (3): 1438-5627. Art. 18. 
Stephan, W. G. 1987. "The Contact Hypothesis in Intergroup Relations." In Review of Personality and Social Psychology, edited by C. Hendrick, 13-40. Beverly Hills: Sage.

Stringer, M., P. Irwing, M. Giles, C. McClenahan, R. Wilson, and J. A. Hunter. 2009. "Intergroup Contact, Friendship Quality and Political Attitudes in Integrated and Segregated Schools in Northern Ireland." British Journal of Educational Psychology 79 (2): 239-

257.10.1348/978185408X368878[CrossRef], [PubMed], [Web of Science ${ }^{\circledR}$ ]

Tatum, B. D. 1992. "Talking about Race, Learning about Racism: The Application of Racial Identity Development Theory in the Classroom." In Racial and Ethnic Diversity in Higher Education, edited by C. Turner, M. Garcia, A. Nora and L. I. Rendon, 150-169. ASHE Reader Series. Needham Heights, MA: Simon \& Schuster.[CrossRef]

Taylor, S., R. Bogdan, and M. DeVault. 2016. Introduction to Qualitative Research Methods: A Guidebook and Resource. 4th ed. New Jersey: Wiley Press.

Walker, I., and M. Crogan. 1998. "Academic Performance, Prejudice, and the Jigsaw Classroom: New Pieces to the Puzzle." Journal of Community and Applied Social Psychology 8: 381393.10.1002/(ISSN)1099-1298[CrossRef], [Web of Science ${ }^{\circledR}$ ], [CSA] 